\title{
Performance Evaluation of New Two Axes Tracking
} PV-Thermal Concentrator

\author{
Luis C. Chea ${ }^{1}$, Håkan Håkansson ${ }^{2}$ and Björn Karlsson ${ }^{3}$ \\ 1. Department of Physics, Eduardo Mondlane University, Maputo 257, Mozambique \\ 2. Architecture and Built Environment, Lund Technical University, Lund SE-221 00, Sweden \\ 3. School of Sustainable Development of Society and Technology, Mälardalen University, Västerås SE 72123, Sweden
}

\begin{abstract}
The overall problem with PV (photovoltaic) systems is the high cost for the photovoltaic modules. This makes it interesting to concentrate irradiation on the PV-module, thereby reducing the PV area necessary for obtaining the same amount of output power. The tracking capability of two-axes tracking unit driving a new concentrating paraboloid for electric and heat production have been evaluated. The reflecting optics consisting of flat mirrors provides uniform illumination on the absorber which is a good indication for optimised electrical production due to series connection of solar cells. The calculated optical efficiency of the system indicates that about $80 \%$ of the incident beam radiation is transferred to the absorber. Simulations of generated electrical and thermal energy from the evaluated photovoltaic thermal (PV/T) collector show the potential of obtaining high total energy efficiency.
\end{abstract}

Key words: Solar concentrating, photovoltaic/thermal systems, tracking concentrating systems.

\section{Introduction}

The increasing demand of energy, the depletion of fossil fuel and the environmental problems associated with the use of fossil fuel make the deployment of alternative renewable energies attractive. Solar photovoltaic energy is one of the promising forms of renewable energy.

The high cost of the solar cells is the main problem limiting the wide utilisation of PV (photovoltaic) technology in the developing countries. One possible solution to the high costs is to concentrate irradiation on the PV modules in order to minimize the required cell area for the same output. However, with increased irradiation concentration, there will be a need for increased cooling of the PV cells in order to lower the working temperature, prevent damage and conserve cell efficiency [1]. Usually, a photovoltaic/thermal (PV/T) concentrating system has a photovoltaic module cooled by air or water. Hence, not only

Corresponding author: Luis C. Chea, M.Sc., research field: solar energy. E-mail: luis.chea@uem.mz. electricity is generated from the absorber but also heat can be utilized that would otherwise be wasted [2]. $\mathrm{PV} / \mathrm{T}$ systems where heat also is utilized to provide a higher total energy output than PV modules and could be cost effective if additional cost of the thermal unit is low [3].

Detailed theoretical models of $\mathrm{PV} / \mathrm{T}$ collectors showing how the outputs are limited by different factors have been developed [4]. The major challenge in designing a concentrating photovoltaic system is to achieve an acceptable radiation flux distribution [5]. Parabolic reflectors often cause high local irradiance and cell temperature resulting in panel power loss [6]. The effect of optical imperfections on the array performance is also discussed by Anton et al. [7].

Three-dimensional concentrating systems require sun tracking within a narrow angle cone to work by directing the direct sunlight to the reflecting optics. In low concentrating applications, a portion of diffuse light from the sky can also be captured [8]. The physics behind the concentrating solar systems requires that tracking accuracy increases as the system 
concentration ratio increases [9]. In high concentrations, the tracking accuracy should be in the $\pm 0.1^{\circ}$ range to deliver approximately $90 \%$ of the rated power output, while in low concentrating systems it should be in the $\pm 2.0^{\circ}$ range [10].

In the present work, we evaluate the tracking capability of two-axes tracking unit coupled to a concentrating $\mathrm{PV} / \mathrm{T}$ system installed at Lund University. The optical system of the collector was analyzed and the electrical energy and the heat that the system would produce is simulated for three different sites.

\section{Description of a Two-Axes Tracking Hybrid Concentrator}

The Swedish Company GSE (Global Sun Engineering) has developed a rather unique 2-axis tracking and concentrating hybrid based on flat mirrors named Matarenki Light. The hybrid is constructed around $2 \times 9$ flat mirrors in a parabolic geometry (Fig. 1a). The mirrors work constructively acting as a doubly curved shell together with the steel frame (Fig. 1b). The mirrors surface has its largest projected width $3.0 \mathrm{~m}$ and height $1.7 \mathrm{~m}$. The distance between the mirror halves is $0.48 \mathrm{~m}$ and the focal length of the paraboloid is $1.47 \mathrm{~m}$. The absorbers are $16.5^{\circ}$ inclined towards each mirror array.

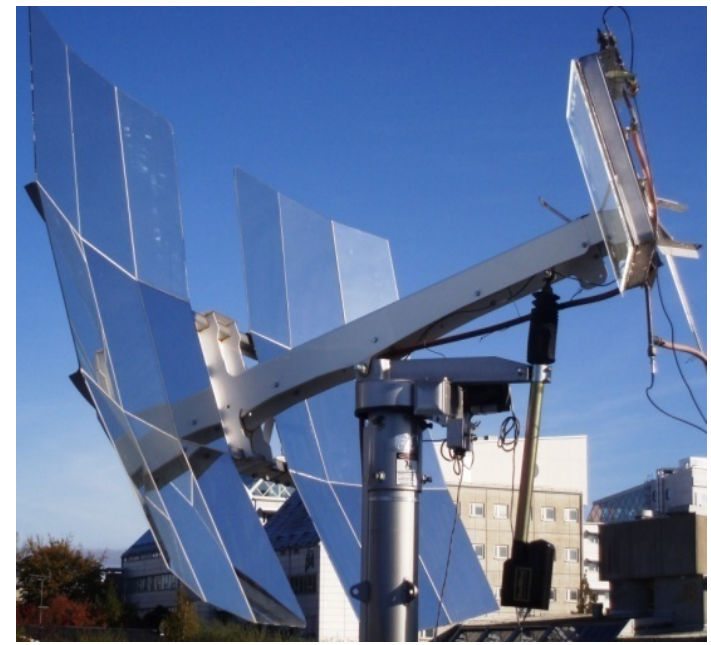

(a)
Solar cells connected in series demand a uniform irradiation distribution and this is met using flat mirrors in this design. The absorber is made from two parallel sheets of stainless steel to get an even dissipation of heat. The absorber is isolated on the back side and covered with a front glass. Silicon cells are not yet laminated on the absorber.

A Wattsun AZ 125 two axes tracking unit [11] meant for flat solar panels is used for the tracking system. Azimuth tracking is made by rotating the reflectors around the centre pole, while the tilt is given by the elevation actuator. The tracker is powered by 24 V DC. Light sensors are placed on the four sides of a box and opposing sensors receive equal amount of brushing light from the direct component of the light from the sun when tracking is reached. An additional sensor on top of the box senses the dusk so the tracking can return to an east position after dark (Fig. 2).

\subsection{Geometry and Light Distribution}

Conventional two dimensional concentrating systems are constructed around a parabolic trough and three dimensional systems are built around parabolic dishes. This system is made up of flat mirrors in facet mounting. Fig. 3 shows the overall mirror dimensions at the centre of the mirror.

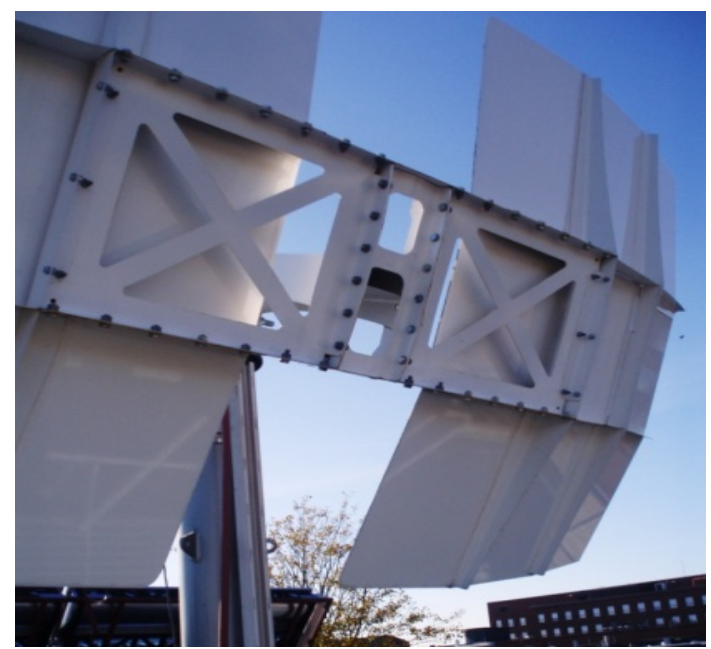

(b)

Fig. 1 Two axes tracking and concentrating PV/T: (a) front view of the collector with one of the absorbers mounted; (b) backside of the collector showing how it is connected with the steel frame. 


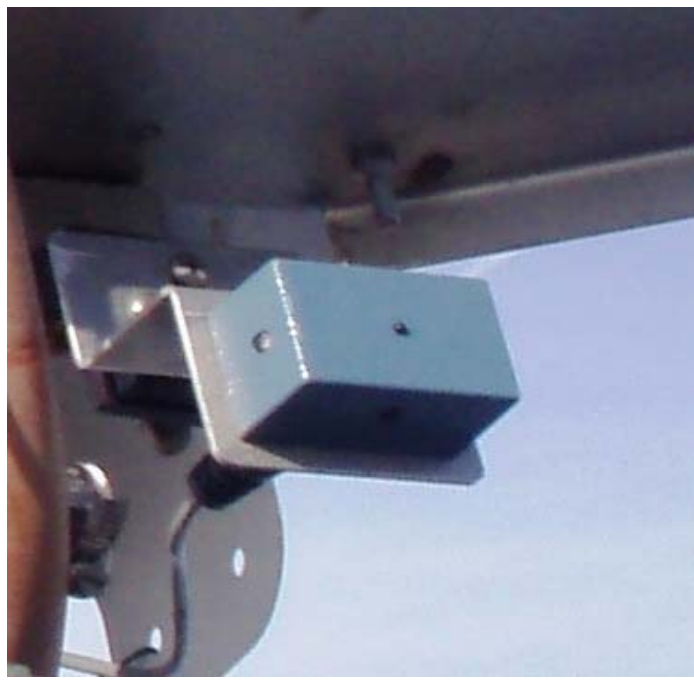

Fig. 2 Box with light sensors.

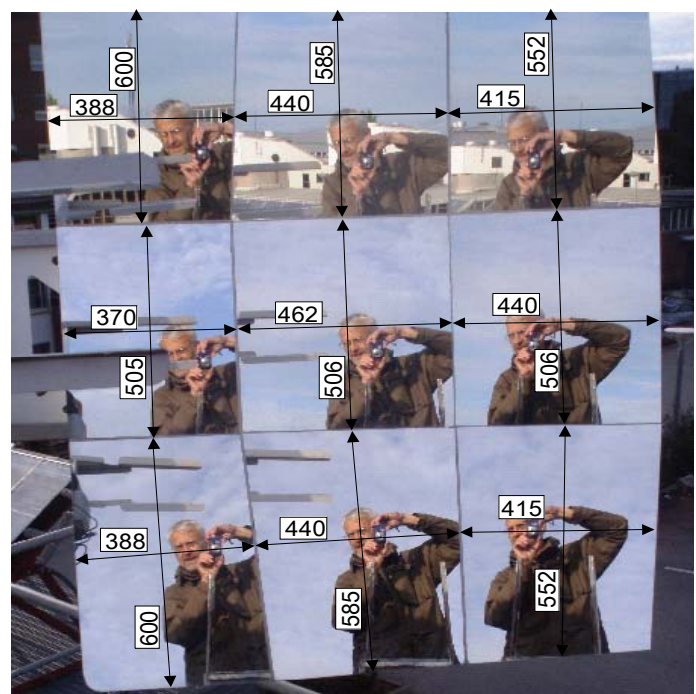

Fig. 3 Picture taken from the double focal length (without absorber).

To analyze the light distribution over the absorber, all mirrors were covered except one that gives the image on the absorber. Then the image was photographed and the process repeated for all mirrors in the right mirror set (Fig. 4).

In Fig. 4a, the uncovered mirror reflects the blue sky, whereas in Fig. 4b, the uncovered mirror reflects a white cloud. The mirror in the middle row left is always shaded by the absorber.

\subsection{Estimation of Concentration Factor of the System}

Fig. 5 shows the shaded areas on the absorber from the irradiation for all individual mirrors based on photos and seen from the sun as in Fig. 3. The central part of the absorber is irradiated with contribution from the direct solar radiation multiplied with the cosine of incident angle from each individual 8 active mirrors. The values are shown in Fig. 5. This gives a geometrical concentration factor for the central parts of the absorber, assuming ideal mirrors and it can be estimated according to:

$$
C=\sum \cos \left(\theta_{i}\right)
$$

where, $C$ is the geometrical concentration factor and $\theta_{i}$ is the angle of incidence in each active mirror. From Fig. 5, the concentration factor will be:

$$
1+0.96+2 \times 0.91+2 \times 0.95+2 \times 0.92=7.52
$$

The ASTM G173 standard [12] gives the total and direct spectral irradiation for standardized tilted surface and is the spectral reference for the definition of solar cell efficiency. The spectral distribution for the direct irradiation is shown in Fig. 6. Minor contribution in the $2,500 \mathrm{~nm}$ to $4,000 \mathrm{~nm}$ range is not shown in the diagram.

Standard glass with iron content is used for the mirrors and as a cover for the absorber. The transmission trough the $4 \mathrm{~mm}$ glass mirrors and the 2 $\mathrm{mm}$ glass cover corresponds roughly to the transmission trough a $10 \mathrm{~mm}$ single pane window. The measured spectral transmission for $10 \mathrm{~mm}$ glass taken from Parasol building simulation program [13] is multiplied with the spectral direct irradiation and gives $643 \mathrm{~W} / \mathrm{m}^{2}$ integrated over the whole range of the solar spectrum. The direct integrated irradiation is 900 $\mathrm{W} / \mathrm{m}^{2}$ giving a reduction factor of 0.71 for the influence from the glass for solar heat.

The efficiency of a solar cell is defined in the standard with the direct and the diffuse irradiation of $1,000 \mathrm{~W} / \mathrm{m}^{2}$. With an assumed sensitivity for $\mathrm{Si}$, a spectral calibration curve was calculated to give the electrical output for the desired efficiency. This spectral calibration curve can then be used to calculate the electrical output for the actual direct spectrum in the concentrator with ideal mirrors alternatively with the influence of glass (Fig. 6). 


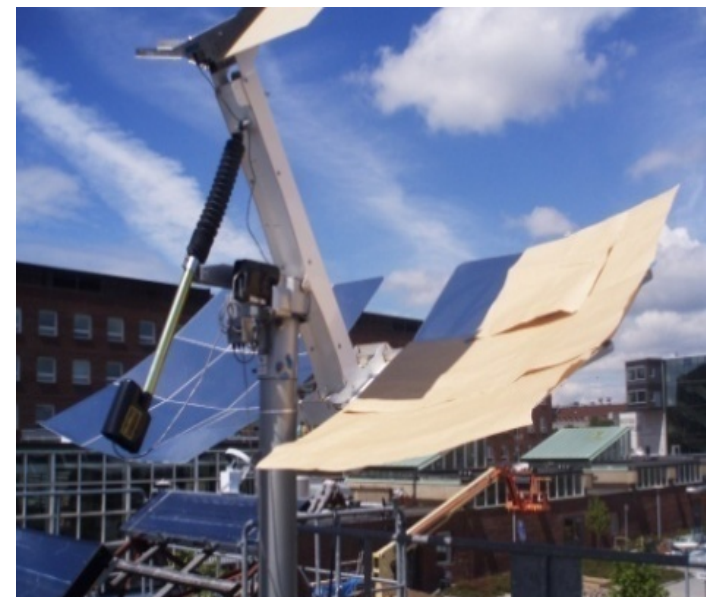

(a)

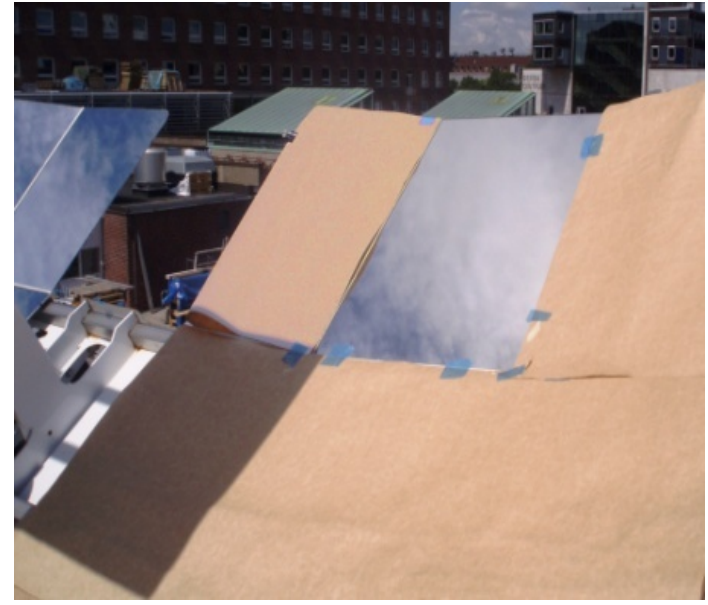

(b)

Fig. 4 Measuring the contribution of individual mirrors on the absorber: (a) left mirror is active in top row; (b) middle mirror is active in top row.

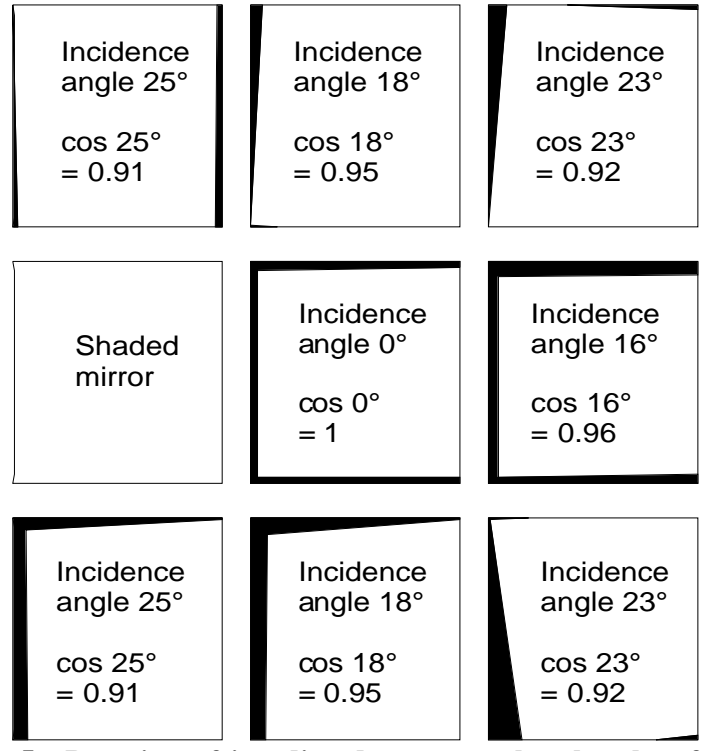

Fig. 5 Drawing of irradiated areas on the absorber from individual mirrors based on photos, the incidence angle from the mirror on the absorber is specified.

Similarly the integrated value of transmission weighted against an assumed sensitivity of Si gives $162 \mathrm{~W} / \mathrm{m}^{2}$ and the reduction factor is 0.72 for the influence from the glass for solar electricity.

For this type of design, inevitable triangular shaded areas are obtained. From Fig. 5, 2\% of the absorber area is estimated to be shaded in this way. Most of the triangular part of shading in Fig. 5 is assumed to be reduced by adjustments.

The absorber area is $440 \mathrm{~mm} \times 530 \mathrm{~mm}$ giving an area of $0.24 \mathrm{~m}^{2}$. An active aperture area for the two halves is $2 \times 0.24 \times 7.52 \times 0.98=3.54 \mathrm{~m}^{2}$.

\subsection{Evaluation of Tracking Capability}

An additional angle sensor only sensitive in a narrow angle cone was developed to analyze the tracker performance in the vertical and horizontal directions. It is shown in Fig. 7, for each direction, a thin aperture slot is placed at the top of the box generating a light spot on a PSD (position sensitive device) at the base of the box. It consists of a stretched out photodiode with a common cathode and separate anodes at each end. By comparing the two currents produced by the small spot of light, a position of the spot and hence the incidence angle can be calculated. For small angles, the deviation angle, $\Delta \varphi$, in degrees is given by:

$$
\Delta \varphi=\frac{L}{2 d}\left(\frac{180}{\pi}\right) \frac{I_{1}-I_{2}}{I_{1}+I_{2}}
$$

where, $L$ is length of PSD sensor, $d$ is the distance from the sensor to the aperture, and $I_{1}, I_{2}$ are the currents from each end of the photodiode. Accordingly, horizontal angular deviation $\Delta \varphi_{h}$ and vertical angular deviations $\Delta \varphi_{v}$ can be calculated.

Additionally, a mechanical angle sensor consisting of a potentiometer was mounted so that the rig elevation angle was recorded. This means that the tracking capability could be controlled. 


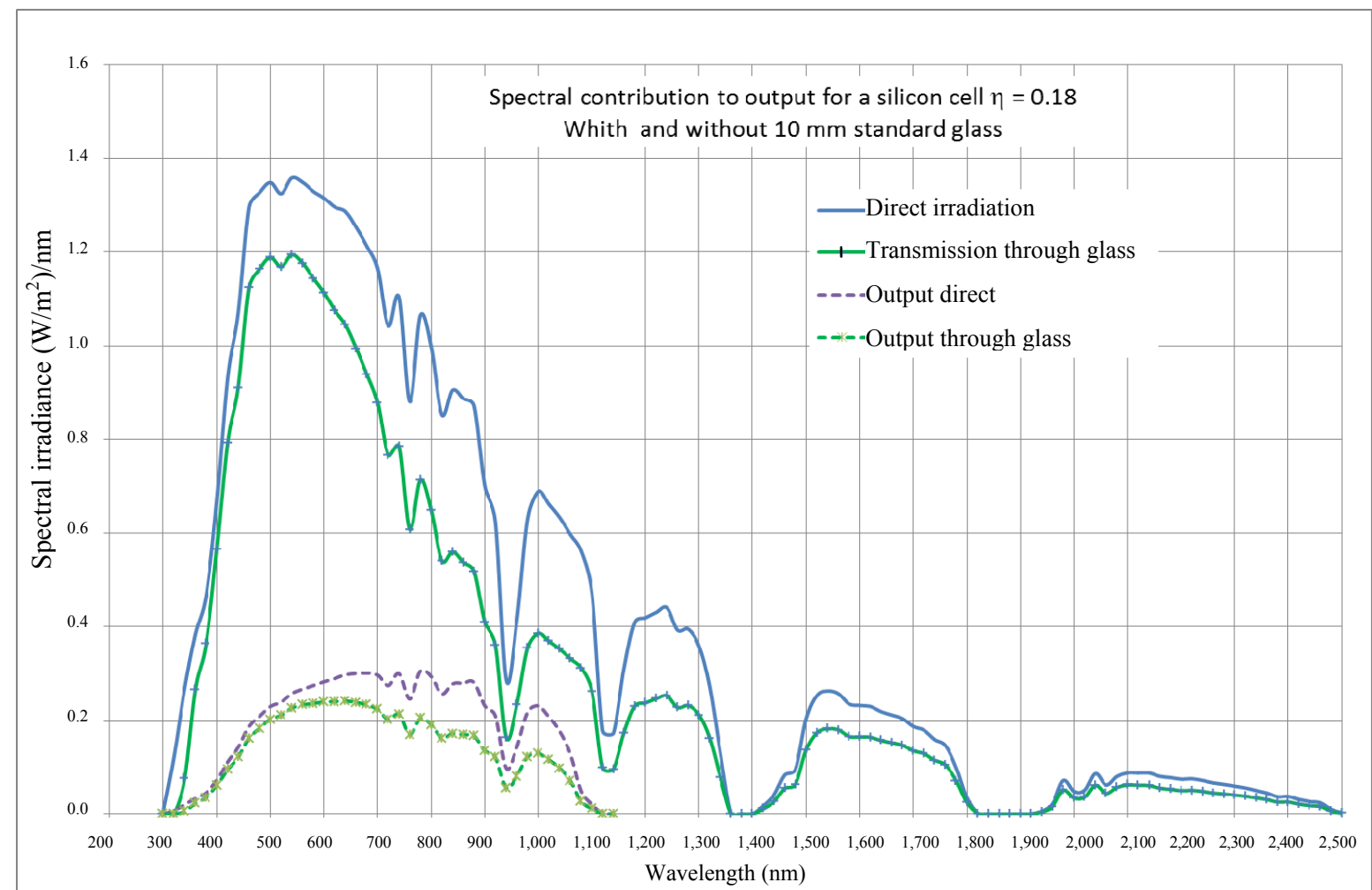

Fig. 6 The spectral influence from $10 \mathrm{~mm}$ glass: (a) direct irradiation; (b) direct irradiation through $10 \mathrm{~mm}$ standard glass; (c) spectrally differentiated output from a solar cell in direct solar irradiation; (d) spectrally differentiated output from a solar cell in direct solar irradiation through $10 \mathrm{~mm}$ glass.

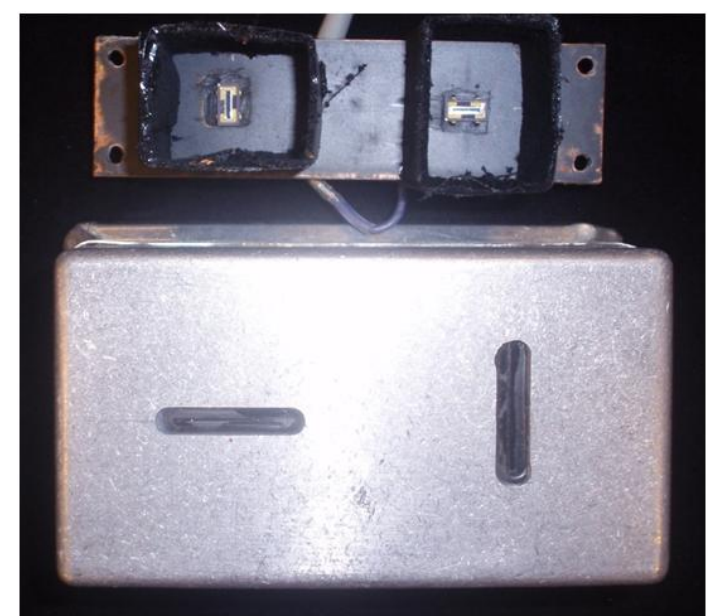

(a)

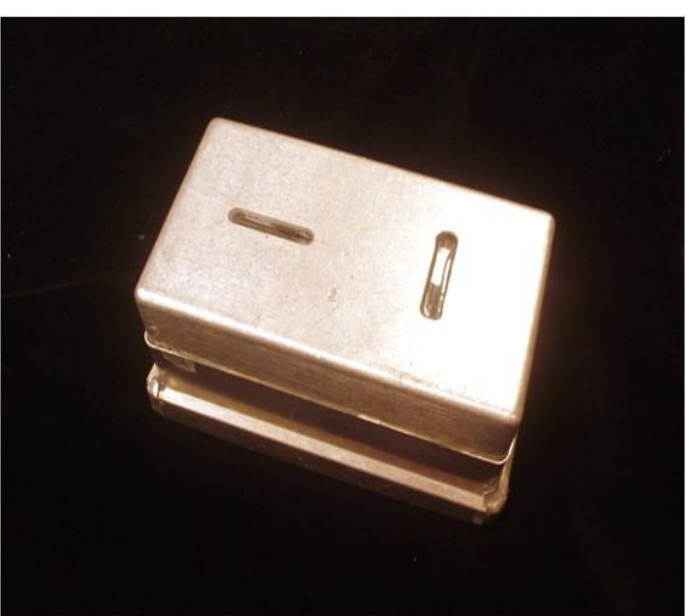

(b)

Fig. 7 View of an optical sensing box: (a) with the PSD sensors at the base of the box; (b) the complete angle deviation sensor.

\section{Experimental Results and Simulation of Energy Output}

\subsection{Experimental Results}

Fig. 4a shows that the shaded mirror is just due to the absorber outline indicating a correct size of the absorber. If the dimensions of the absorber exceed the design dimensions, three mirrors would be shaded causing substantial drop of the reflected light.

Measurements of incident angle given by individual mirrors on the absorber and shown in Fig. 5, enabled to estimate the geometrical concentration, which is 
found to be 7.52. The practical concentration factor was found by calculating the ratio of measured intensity of solar radiation on the absorber to direct solar radiation on the collector plan. The averaged values of solar radiation measured in these two plans were $4,810 \mathrm{~W} / \mathrm{m}^{2}$ and $811 \mathrm{~W} / \mathrm{m}^{2}$, giving an average practical concentration value of 6.0. This means that the optical efficiency of the collector is 0.797 .

From the measurements with photodiodes, we found the angular deviations from the direction of light beam, both in horizontal and vertical plan. Fig. 8 shows horizontal angular deviations during a clear day with occasional clouds. If the value of optical position providing vertical deviations is added to the value of the mechanical angle sensor, the solar height is determined with good accuracy. This is illustrated in Fig. 9, where theoretical, measured and measured and corrected solar height is represented. The relatively small horizontal deviation angles and the good match between real and measured solar height, indicate that the tracking unit works fine during clear days.

On partly cloudy days however, unnecessary energy losses could be expected and added risks for the durability of the electrical bypass system.

Because of the concentration, the collector must have a temperature sensor that sends signals to the controller to defocus the mirrors at excessive temperatures. This would protect from stagnation temperatures.

\subsection{Simulations of Energy Output}

Simulations of the expected thermal and electrical output for Stockholm, Madrid and Maputo have been performed. In these simulations, it was assumed that the system is equipped with solar cells with a conversion efficiency of $18 \%$. The system optical efficiency is assumed to be 0.80 . Furthermore, it was assumed that the solar thermal collector has an optical efficiency of 0.60 and U-value of $1.6\left(\mathrm{~W} / \mathrm{m}^{2} \cdot \mathrm{K}\right)$, calculated by the collector aperture area. This means that $80 \%$ of the direct solar radiation on the mirrors reaches the solar cells and $18 \%$ of incident radiation is converted into electricity and the rest becomes heat, about $60 \%$. Heat production is estimated at an average operating temperature of $50{ }^{\circ} \mathrm{C}$.

Electrical and thermal energy per unit area is calculated according to Eqs. (3) and (4):

$$
\begin{gathered}
E_{e l}=\eta_{o b-e l} K_{b-e l}(\theta) H_{b}+\eta_{o b} K_{d} H_{d} \\
E_{t h}=\eta_{o b-t h} K_{b-t h}(\theta) H_{b}+\eta_{o b} K_{d}(\theta) H_{d}-U \Delta T
\end{gathered}
$$

In these equations, $\eta_{o b}$ is the electrical/thermal optical efficiency for beam radiation, $K_{b}$ is the

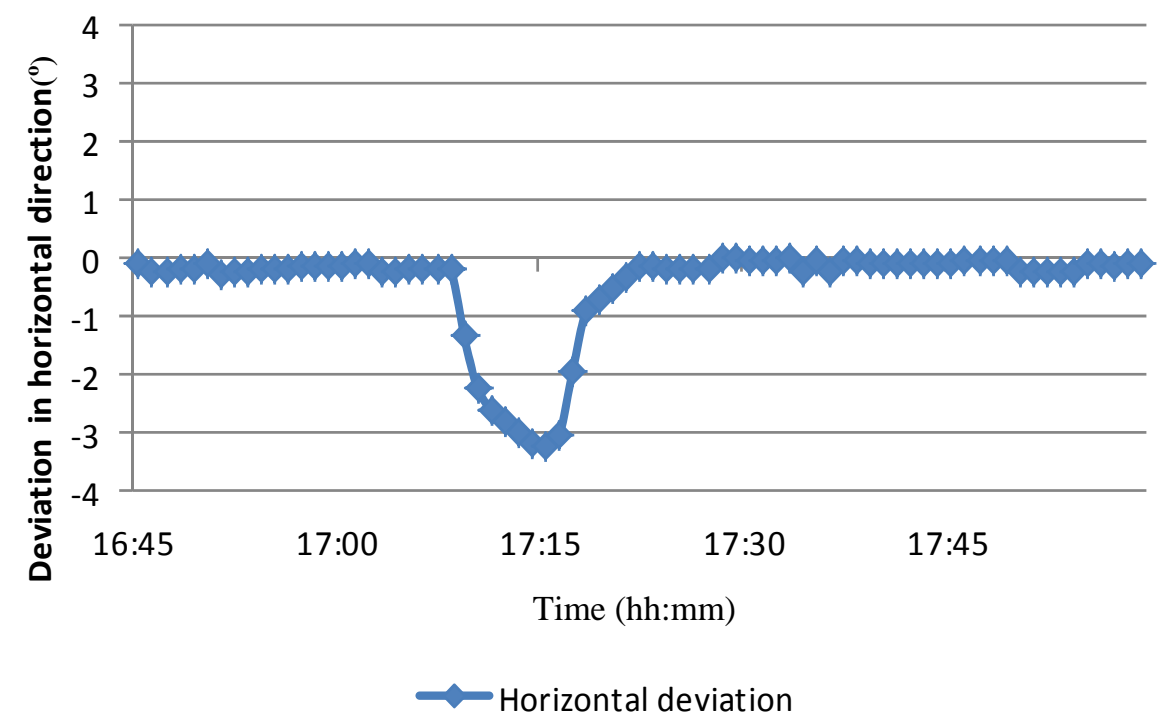

Fig. 8 Angular horizontal deviation of solar tracking during a cloud (hunting event) measured by an optical sensor. 


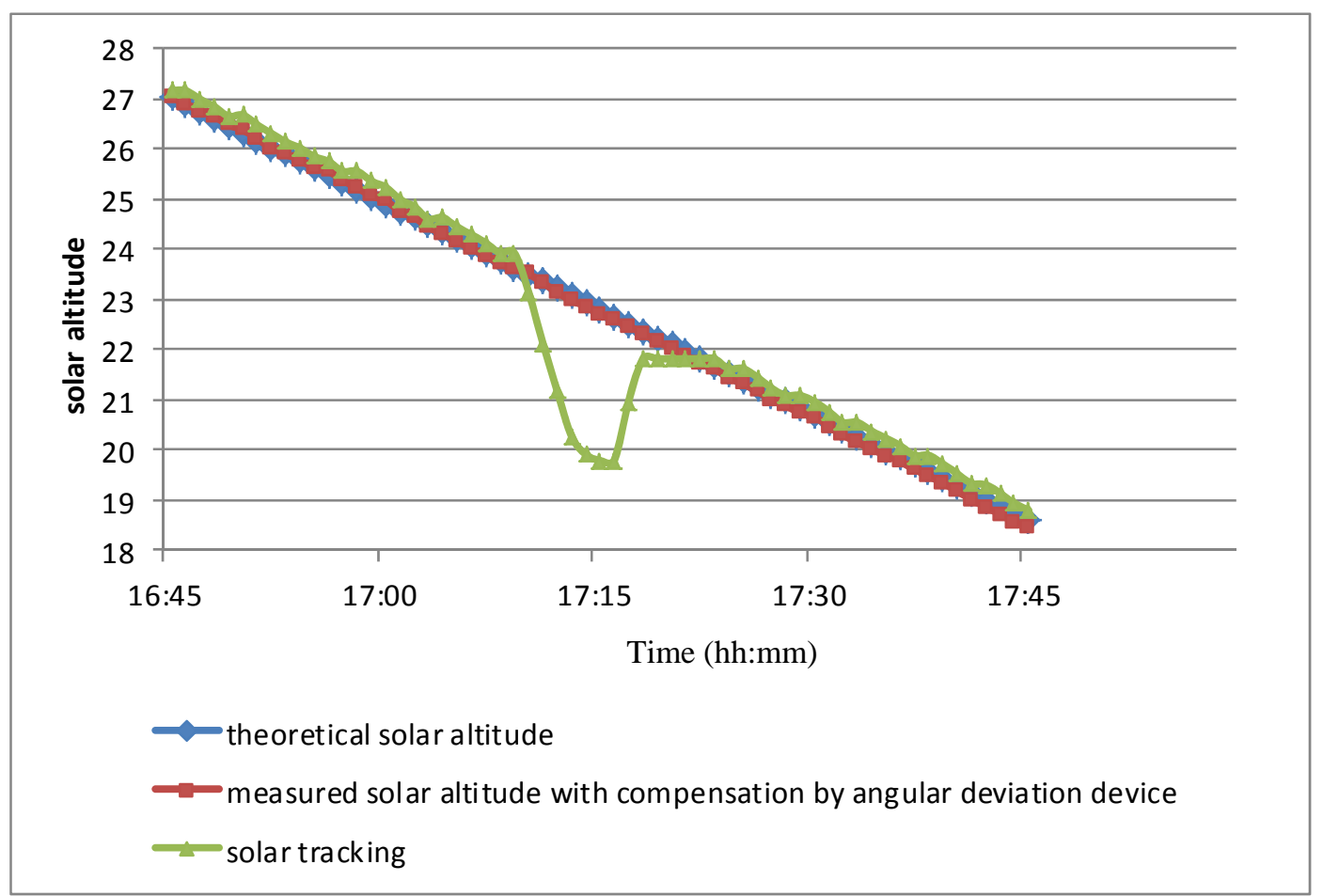

Fig. 9 Vertical tracking for the same event as in Fig. 8: real solar altitude; measured solar altitude and compensate by vertical deviation; measured solar altitude.

electrical/thermal incidence angle modifier for beam radiation, defined by Eq. (5), $H_{b}$ is the beam irradiation, $K_{d}$ is the incidence angle modifier for diffuse radiation, $H_{d}$ is the diffuse irradiation, $U$ is the overall heat loss coefficient which is defined by Eq. (6) and $\Delta T$ is the temperature difference between mean collector temperature and the ambient temperature. The incidence angle modifier for beam radiation for incidence angles between $0^{\circ}$ and $60^{\circ}$ is given by:

$$
K_{b}(\theta)=1-b_{0}(1 / \cos \theta-1)
$$

where, $b_{0}$ is the electrical/thermal angular coefficient. The diffuse incidence angle modifier was calculated as being the inverse of the concentration ratio, and the $U$-value is given by:

$$
U=a_{1}+a_{2} \Delta T
$$

where, $a_{1}$ is the constant part of the overall heat loss coefficient, and $a_{2}$ is the temperature dependent part of the overall heat loss coefficient.

Simulations were performed for a flat PV module, vacuum tube, both at optimum tilt $\left(40^{\circ}\right.$ for Stockholm, $30^{\circ}$ for Madrid and $26^{\circ}$ for Maputo), tracking concentrating PV module and tracking concentrating solar collector representing the evaluated $\mathrm{PV} / \mathrm{T}$ tracking concentrator. For vacuum tubes, the parameters are: optical efficiency of 0.80 and $U$-value $2\left(\mathrm{~W} / \mathrm{m}^{2} \cdot \mathrm{K}\right)$. Here, we assume that it is a vacuum tube with flat absorber inside so that single sided absorber area is used as the defined area.

The results show that the global solar irradiation on a fixed surface towards equator is higher than the direct solar radiation on a surface with two axes tracking and it is independent of latitude. This is derived from Fig. 10.

A global sun engineering system with an area of $3.54 \mathrm{~m}^{2}$ provides:

(1) $1,070 \mathrm{kWh} / \mathrm{yr}$ of electricity and 3,600 kWh/yr of heat in Madrid. The system can be replaced in Madrid by approximately $3.5 \mathrm{~m}^{2}$ of flat PV modules and 3.5 $\mathrm{m}^{2}$ of vacuum tubes in order to produce the same amount of energy;

(2) $600 \mathrm{kWh} / \mathrm{yr}$ of electricity and 2,000 kWh/yr of heat in Stockholm. The system can be replaced by 3 


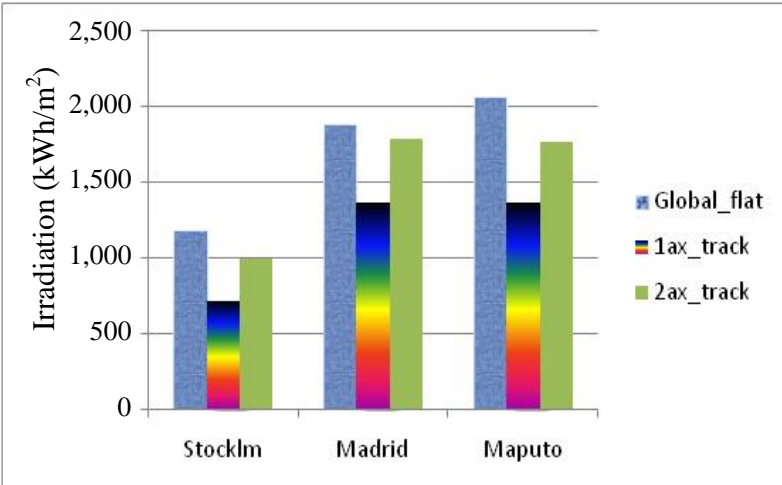

Fig. 10 Global solar irradiation on inclined surfaces towards equator, direct irradiation on surfaces with east-west and two axes tracking in Stockholm, Madrid and Maputo.

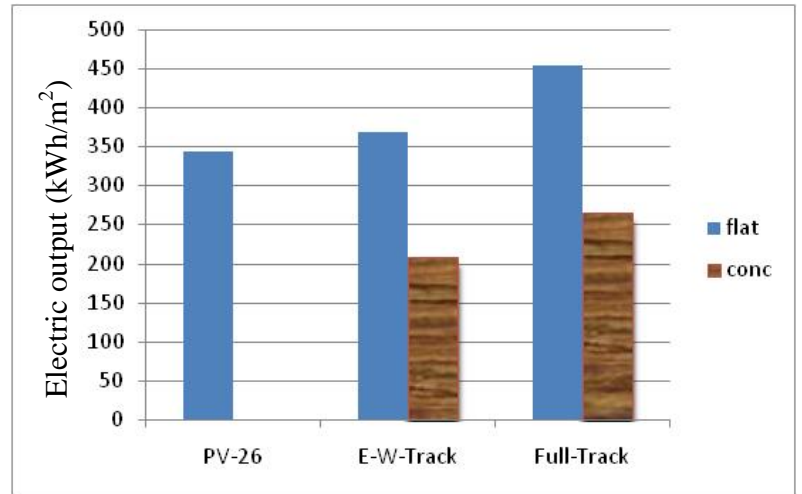

Fig. 11 Electric power delivered by PV modules: inclined $26^{\circ}$ North, tracking around an east-west axis, tracking in two axes and concentrating PV plus tracking in Maputo.

Table 1 Energy output of flat PV, vacuum tubes, concentrating PV and concentrating solar collector in three different locations.

\begin{tabular}{lllll}
\hline Stockholm & $\begin{array}{l}\text { Vacuum tubes } \\
\left(\mathrm{kWh} / \mathrm{m}^{2}, \mathrm{yr}\right)\end{array}$ & $\begin{array}{l}\text { Output concentrated PV } \\
\text { module }\left(\mathrm{kWh} / \mathrm{m}^{2}, \mathrm{yr}\right)\end{array}$ & $\begin{array}{l}\text { Flat PV module } \\
\left(\mathrm{kWh} / \mathrm{m}^{2}, \mathrm{yr}\right)\end{array}$ & $\begin{array}{l}\text { Output concentrated solar } \\
\text { collector }\left(\mathrm{kWh} / \mathrm{m}^{2}, \mathrm{yr}\right)\end{array}$ \\
\hline $\begin{array}{l}\text { 40 } \text { tilt } \\
\text { E-W tracking }\end{array}$ & 639 & - & 195 & - \\
Full tracking & 704 & 111 & 212 & 335 \\
Madrid & 947 & 152 & 271 & 511 \\
$30^{\circ}$ tilt & & & & - \\
E-W tracking & 1,194 & - & 312 & 606 \\
Full tracking & 1,296 & 199 & 337 & 918 \\
Maputo & 1,722 & 268 & 412 & - \\
$26^{\circ}$ tilt & & & & 698 \\
E-W tracking & 1,390 & - & 344 & 970 \\
Full tracking & 1,494 & 208 & 366 & 454 \\
\hline
\end{tabular}

$\mathrm{m}^{2}$ of flat PV modules and $3 \mathrm{~m}^{2}$ of vacuum tubes;

(3) $1,060 \mathrm{kWh} / \mathrm{yr}$ of electricity and 3,880 kWh/yr of heat in Maputo. The system can be replaced by $3.2 \mathrm{~m}^{2}$ of flat PV modules and approximately $3 \mathrm{~m}^{2}$ of vacuum tubes.

The electrical and thermal output for the three different sites is summarized in Table 1. For Maputo, the electrical outputs are represented in Fig. 11.

\section{Conclusions}

An advanced two-axes tracking solar concentrating system producing both electricity and heat was developed by the Swedish company Global Sun Engineering. Flat mirrors provide uniform light intensity on the absorber with solar cells. A prototype of this system has been installed on the roof at Lund
University, aiming to evaluate the complete system.

The evaluation shows that the flat mirrors provide uniform illumination on almost the entire area of the absorber. The tracking unit works with good accuracy on clear days. However, for a partly clouded day, unacceptable deviation (hunting) occurs. This is planned to be solved by sensing the currents from opposing solar cells on the borders of the absorber for fine tuning of the tracking.

Simulations of the system have been made with certain assumptions about the system performance. The results show that:

- The global solar radiation on fixed surface inclined to an optimal angle towards equator is higher than the direct radiation on a surface with two axes tracking, in all latitudes; 
- The analyzed PV/T system with an area of 3.54 $\mathrm{m}^{2}$ would produce approximately $1,060 \mathrm{kWh} / \mathrm{yr}$ of electricity and 3,800 kWh/yr of heat in Maputo. In Stockholm, the system would produce approximately half of these figures. To produce the same amount of energy, the system can be replaced by $3.2 \mathrm{~m}^{2}$ of PV modules and $3 \mathrm{~m}^{2}$ of vacuum tubes in Maputo.

\section{References}

[1] J. Nilsson, H. Håkansson, B. Karlsson, Electrical and thermal characterization of a PV-CPC hybrid, Solar Energy 81 (7) (2007) 917-928.

[2] L.R. Bernardo, B. Perers, H. Håkansson, B. Karlsson, Performance evaluation of low concentrating photovoltaic thermal systems: A case study from Sweden, Solar Energy 85 (7) (2011) 1499-1510.

[3] Y. Tripanagnostopoulos, M. Souliotis, R. Battisti, A. Corrado, Application aspects of hybrid PV/T solar systems, http://www.enc.nl/fileadmin/ecn/units/egon/pvt/ pdf/eurosun04_lca.pd (accessed Apr. 21, 2010).

[4] J.S. Coventry, K. Lovegrove, Development of an approach to compare the "value" of electrical and thermal output from domestic PV/thermal, Solar Energy 75 (2003) 63-72.

[5] J.S. Coventry, Performance of a concentrating photovoltaic/thermal solar collector, Solar Energy 78 (2004) 211-222.

[6] I. Anton, R. Solar, G. Sala, D. Panchó, Testing of concentrating modules and cells with non-uniform light patterns, http://www.ies-def.upm.es/ies/CRATING /Vc237.pdf (accessed June 18, 2012).

[7] I. Anton, G. Sala, J.C. Arboiro, J. Mondero, P. Valera, Effect of the optical performance on the output power of the Euclides array, in: 16th European Photovoltaic Solar Energy Conference, Glasgow, 2000, pp. 2225-2228.

[8] J.A. Duffie, W.A. Beckman, Solar Engineering of Thernal Process, John Wiley \& Son, USA, 2006.

[9] R. Winston, J. Minãno, P. Benítez, Nonimaging Optics, Academic Press, USA, 2005.

[10] Concentrated Photovoltaic Trackers, http://en.wikipedia.org/wiki/Solar_tracker\#Concentrated_ photovoltaic_.28CPV.29_trackers (accessed May 5, 2012).

[11] Wattsun Solar Tracker Installation Guide, www.wattsun.com (accessed Mar. 10, 2010).

[12] ASTM G173 Standard, http://pveducation.org/pvcdrom/appendicies/standard-sol ar-spectra (accessed May 12, 2012).

[13] Parasol Building Energy Simulation Program, http://www.ebd.lth.se/english/software/parasol/ (accessed May 15, 2012). 